\title{
Benefits or Risks: What Influences Novice Drivers Regarding Adopting Smart Cars?
}

\author{
Areej Ahmad Alshaafee ${ }^{1,2, *}$, Noorminshah A. Iahad ${ }^{3,4}$ (D) and Mohammed A. Al-Sharafi ${ }^{3}[$ \\ 1 School of Computing, Faculty of Engineering, Universiti Teknologi Malaysia, Skudai 81310, Malaysia \\ 2 Information Systems, Faculty of Computing, King Khalid University, Abha 61114, Saudi Arabia \\ 3 Department of Information Systems, Azman Hashim International Business School, Universiti Teknologi \\ Malaysia, Skudai 81310, Malaysia; minshah@utm.my (N.A.I.); alsharafi@ieee.org (M.A.A.-S.) \\ 4 Information Systems, Faculty of Science and Technology, Universitas Airlangga, Surabaya 60115, Indonesia \\ * Correspondence: areej@kku.edu.sa
}

check for

updates

Citation: Alshaafee, A.A.; Iahad, N.A.; Al-Sharafi, M.A. Benefits or Risks: What Influences Novice Drivers Regarding Adopting Smart Cars? Sustainability 2021, 13, 11916. https://doi.org/10.3390/ su132111916

Academic Editors: Ahmed F. Zobaa, Shady H. E. Abdel Aleem and Foad Heidari Gandoman

Received: 22 September 2021

Accepted: 22 October 2021

Published: 28 October 2021

Publisher's Note: MDPI stays neutral with regard to jurisdictional claims in published maps and institutional affiliations.

Copyright: (c) 2021 by the authors. Licensee MDPI, Basel, Switzerland. This article is an open access article distributed under the terms and conditions of the Creative Commons Attribution (CC BY) license (https:// creativecommons.org/licenses/by/ $4.0 /)$.

\begin{abstract}
Level 4 autonomous vehicles (AVs) are smart vehicles that can move between two different points without any human interference. In 2018, the Saudi Arabian ban on female drivers was finally lifted, resulting in a large number of novice women drivers of different ages. The Kingdom might therefore be considered a risky place to drive, but AVs would help novices to reduce their fear of driving and reduce accidents. Previous studies focused narrowly on those who already had sufficient driving experience and held a valid driving license, but there were no studies on the adoption of smart cars by novice drivers. Based on a literature search, no studies had used a net valence model (NVM) for the adoption of AVs to understand their benefits/risks. Therefore, this study proposed an adoption model for AVs using an NVM to identify the benefit and risk factors that have an impact on beginner drivers' adoption of autonomous vehicles. A survey method was applied using the purposive sampling technique. Data were collected from 1400 female Saudi novice drivers who had experience with driving AVs. Data analysis was performed using Smart PLS Version 3. The results showed that individuals tended to ignore potential risks and focus instead on the potential benefits of using AVs. Performance expectancy, enjoyment, and effort expectancy were found to be positively related to the perceived advantages. On the other hand, the perceived risk as a construct did not have an impact on beginner drivers' adoption of autonomous vehicles. Therefore, the major theoretical contribution of this study was the formation of a new NVM model by incorporating three more constructs, which were social influence, personal innovativeness, and alternatives. Finally, the enhanced NVM model could assist AV developers in identifying the expected benefits and drawbacks of AV adoption.
\end{abstract}

Keywords: artificial intelligence; alternatives; autonomous vehicles; net valence model; personal innovativeness; social influence

\section{Introduction}

Artificial intelligence (AI) uses hundreds of digital videos and images to simulate human intelligence [1]; AI is about building smart machines that can perform human tasks. One application of AI in this regard is autonomous vehicles (AVs), which can drive themselves like humans do [2]. To provide a realistic context on how AI is influencing AVs globally, autonomous driving and autonomous cars are currently among the most intensely researched and publicly watched technologies in the transportation field [2]. AVs solve several driving issues, with benefits such as safety, effectiveness, and mobility [1]. AVs are constructed to improve vehicle control by minimizing human mistakes and by providing safety and superior driving [3] by using various innovations, including autonomous cruise control, adaptive high beam, collision avoidance, automatic parking, automotive navigation, driver drowsiness detection, wrong-way driving warning, and intelligent speed adoption [2]. The Saudi Vision 2030 agenda aims to embrace every upcoming innovation in 
automation and robotics [4]. As reported in the Dubai News [5], "Autonomous automobiles are on experimentation in Dubai as the population of Saudis exist there," while Mideast Beast News [6] commented on Google selecting Saudi Arabia as the preferred nation in which to launch the Google car. In June 2018, the Saudi government finally lifted the driving ban on Saudi females [7]. However, because the ban has been in place for so long, the Kingdom is currently dealing with a large number of inexperienced drivers of various ages [8]. The adoption of AVs could help beginner motorists to overcome their panic and drive with safety [9]. However, intelligent technologies are incapable of performing intelligent activities such as ethical judgments, reasoning, situation management, or ideation [1]. Furthermore, there are other possible obstacles to KSA's adoption of AVs, including traffic management, infrastructure, and liability insurance [4]. As a result, there is a chance that Saudi females, who represent a very big sample of novice drivers in Saudi Arabia [7], might reject the adoption. Therefore, this study aimed to measure to what extent novice drivers are willing to adopt AVs in the future. In this study, a novice driver was defined as a driver who had a year or less of driving experience [10]. The details regarding the requirements for individuals and the AVs selected for this study were as follows: (1) participants needed to be female novice drivers who had a year or less of driving experience and they needed to have experienced AVs prior to this study taking place; (2) the AVs required for this paper were level 4 , which are able to move between two different points with human interference only in the case of an emergency.

A thorough review of the literature on AV adoption revealed several research gaps. First, most research focused on those who already had sufficient driving experience (e.g., [1,3]) or already held a valid driver's license (e.g., [9,11]). However, to the authors' best knowledge, no publications addressed AV adoption from the point of view of novice drivers. Second, research into AV adoption is still in its infancy such that this study is at the forefront in exploring the adoption of this technology in developing countries (e.g., KSA). Third, this study focused on Saudi women drivers, whereas in prior research on AV adoption, most of the participants were male (e.g., [11-13]), which may bias their results. Fourth, the extant literature on AV adoption is largely based on the dominant technology adoption theories, examining the general factors that may influence users regarding adopting AVs (e.g., [1,3,9,11]); no studies identified the benefit/risk factors. To overcome these existing research gaps, a new adoption model was developed by adapting the net valence model (NVM). NVM is one of the social science models that is used to identify the benefit/risk factors that influence the adoption of new technology, such as AVs [14]. The developed model aimed to understand what influences female novice drivers in Saudi Arabia regarding adopting AVs.

The remainder of the paper is organized into seven sections. The second section reviews the literature on $\mathrm{AV}$ adoption and explains the $\mathrm{NV}$ model. The third section gives the proposed hypotheses. The fourth section describes the procedure for building the proposed model and hypotheses, the sample, and the data collection procedure. The fifth section covers the data analysis, the results of the study, and the new NVM, along with the new constructs. The discussion takes place in the sixth section, while the conclusion, theoretical implications, practical implications, limitations, and future work are given in the seventh section.

\section{Theoretical Background}

A literature review indicated that no past studies applied an NVM for the adoption of autonomous vehicles and an understanding of its benefits/risks. Therefore, this study proposed an enhanced adoption model for AVs by incorporating an NVM with three more constructs, namely, social influence, personal innovativeness, and alternative attraction, to bridge this knowledge gap. The previous literature tended to concentrate on the benefits rather than the perceived risk or cost [11,15], the absence of privacy [10,12], or perceived dread [15]. There is no detailed study that concentrated on both the benefits and risks on technological and behavioral grounds to individuals adopting AVs. What research there 
is generally applied a TAM [11-13] or UTAUT [15] models, or a combination of a TAM and NVM [12]. TAM stands for the technology acceptance model, which explains how a user accepts and uses a new technology [11], while UTAUT stands for the unified theory of acceptance and use of technology, which is used to explain acceptance behavior [16]. Further, past research focused on trust in the vehicle as a significant construct in the intent to acquire, paying no attention to other constructs [11-13]. An NVM consists of two essential measures: (1) perceived advantages and (2) perceived drawbacks; see Figure 1. Perceived advantages are given a positive valence, whereas perceived drawbacks are given a negative valence [17].

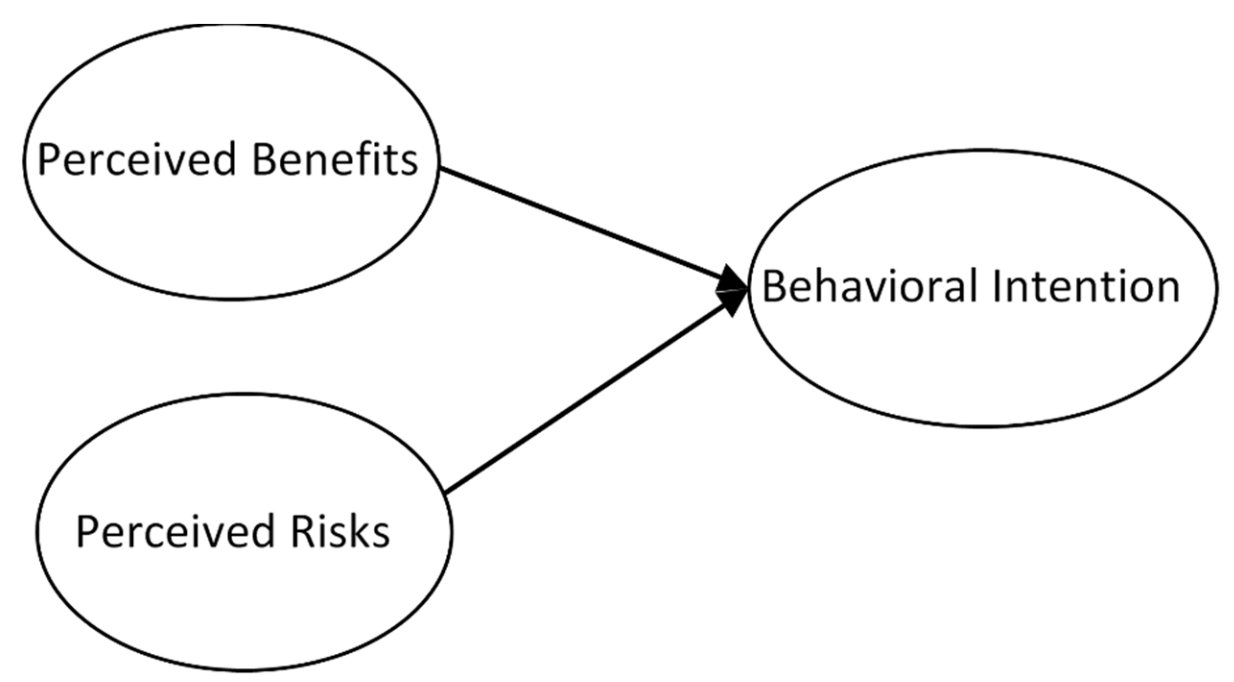

Figure 1. Net valence model [18].

The value adoption model (VAM) is used to measure both risks and benefits toward adopting a new technology [17]. The VAM adds that perceived drawbacks include both monetary and non-monetary constructs [17]. A large number of the participants in previous studies were male, which could have biased the outcomes. Therefore, this study sought to establish the AV adoption constructs (upsides and downsides) from the independent viewpoint of female novice drivers.

\section{Net Valence Model (NVM)}

The NVM was developed by [18] and suggests that if the influence of perceived advantages of an activity is greater than its perceived drawbacks, potential adopters or actual users are more likely to engage in that activity. There are two key variables in an NVM: (1) perceived advantages and (2) perceived threats (see Figure 1). Prior to the introduction of a new technology, several final consumers investigate the benefits and dangers of using it. In the model, perceived advantages are provided a good valence, whereas perceived threats are given a negative valence [17]. In agreement with the VAM, the perceived risks comprise monetary and non-monetary constructs [17].

This study suggested performance expectancy, enjoyment, and effort expectancy as the perceived advantages that apply to AV adoption; see Table 1 for the definitions. Perceived risk factors that apply to AV adoption include security, performance, time, and financial risks; see Table 1 for the definitions. Furthermore, past studies regarding the adoption of a technology in different domains found that the social influence [19], personal innovativeness [20], and alternative attractiveness [21] affected the intention to adopt; see Table 1 for the definitions. However, none of the previous studies on AVs measured these influences. Recognizing this gap, this research was the first to investigate the significance of the advantages/dangers regarding $\mathrm{AV}$ adoption, broadening the NVM with new constructs: personal innovativeness, alternative attractiveness, and social influence. This inquiry concentrated on the potential adopters and not the actual consumers of AVs, and the 
assumption was that the costs and benefits will be considered during the decision to adopt AVs. The proposed model's main conclusion was that if the advantages of adopting an $\mathrm{AV}$ are greater than the relative dangers, the possibility of adopting an AV is greater [18]. Table 1 clarifies the benefits and risks of AVs and their definitions that were examined in this study. This is followed by a definition of each hypothesis.

Table 1. Perceived advantages and risks of AVs.

\begin{tabular}{|c|c|c|}
\hline Category & Construct & Definition \\
\hline \multirow{3}{*}{ Perceived Benefits } & Performance Expectancy & $\begin{array}{l}\text { To what extent a technology can enhance } \\
\text { performance (useful) }\end{array}$ \\
\hline & Enjoyment & $\begin{array}{l}\text { The degree of enjoyment the user feels when utilizing } \\
\text { the innovation }\end{array}$ \\
\hline & Effort Expectancy & The degree of ease while using a technology \\
\hline \multirow{5}{*}{ Perceived Risks } & Security Risk & $\begin{array}{l}\text { The risk that the protection furnished by a system is weak } \\
\text { or non-existent (physical security) }\end{array}$ \\
\hline & Performance Risk & $\begin{array}{c}\text { The risk pertaining to the extent of meeting individual } \\
\text { needs by a particular system is weak or non-existent } \\
\text { (driving output) }\end{array}$ \\
\hline & Time Risk & $\begin{array}{c}\text { The danger that employing some structure could lengthen } \\
\text { the period }\end{array}$ \\
\hline & Financial Risk & $\begin{array}{c}\text { The danger that the cost of acquiring and maintaining a } \\
\text { specified system is greater }\end{array}$ \\
\hline & Psychological Risk & $\begin{array}{l}\text { The danger that employing a certain structure may } \\
\text { negatively affect people's peace of mind or } \\
\text { self-perceptions; panic toward using a new technology }\end{array}$ \\
\hline \multirow{3}{*}{ Extending the NVM } & Alternatives & Other competing alternatives or solutions (personal) \\
\hline & Innovativeness & Consumer's willingness for new technologies \\
\hline & Social Influence & The effect of other people over one's intentions \\
\hline
\end{tabular}

\section{Research Model and Hypothesis Development}

This study proposed a theoretical model by extending the original NVM to predict the individual's intentions to drive AVs. The model presented in Figure 2 suggests that an individual's intention to drive an $\mathrm{AV}$ is supported by their perception of the benefits and hindered by their perception of the risks connected with its use.

\subsection{Perceived Advantages}

Based on previous studies, perceived advantages refer to the benefits that accrue from a system [18]. In the same vein, the present study defined the perceived advantages as the advantages of driving a smart car over a normal car. Research in various fields, such as smart homes [18], social media [22], decision making [23], and fintech adoption [24], indicated that the perceived advantages have a good association with behavioral intention. Hence, this study hypothesized that if people recognize that greater benefits will be derived from using the technology, it is likely that they will adopt it. Accordingly, the following hypothesis was formulated:

Hypothesis (H1). Perceived advantages of AVs have a positive effect on the intention to adopt. 


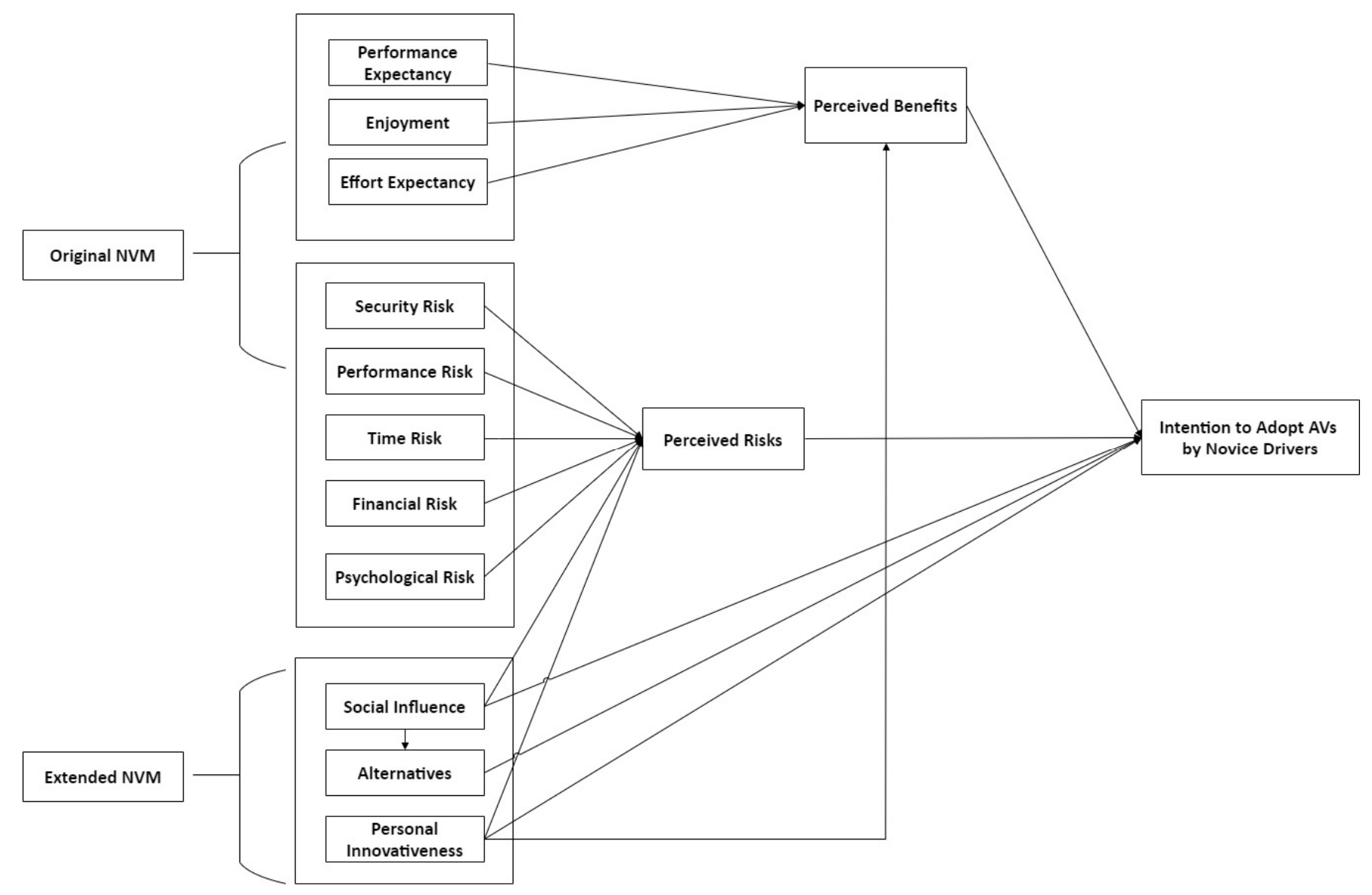

Figure 2. Proposed research model.

\subsubsection{Performance Expectancy}

According to the literature review, performance expectancy refers to perceived usefulness [25]. In the context of this study, it explains the extent to which a person recognizes that using an AV will enhance their driving [26] Performance expectancy includes employing explicit gadgets to sustain the capability to execute improved tasks.

This was exhibited for social networking environments [27]. Based on the VAM [28], usefulness and pleasure are two types of perceived advantages. Therefore, this research suggested that if a person has the expectation that utilizing a technique could sustain performance, they are much more able to have a larger number of advantages linked with it. Accordingly, the following hypothesis was formulated:

Hypothesis (H1a). Perceived performance expectancy has a positive effect on the perceived advantages of $A V$ adoption.

\subsubsection{Enjoyment}

Based on the literature, enjoyment is the intensity of the gratification the user experiences during the utilization of an innovation [18]. The present study defined enjoyment as the extent to which a driver can enjoy driving an AV. In the area of biometric innovation, perceived enjoyment became the key motivation for adopting the desired innovation by actual consumers and prospective adopters, with a strong influence on perceived advantages [29]; this was similar regarding smart homes [28]. This study proposed that people are more willing to select technology that enhances their gratification of perceived advantages. Accordingly, the following hypothesis was formulated: 
Hypothesis (H1b). Perceived enjoyment has a positive impact on the perceived advantages of $A V$ adoption.

\subsubsection{Effort Expectancy}

According to the previous studies, effort expectancy refers to the intensity of the perceived ease of use when utilizing an innovation [30]. In the context of this study, this meant the ease of driving AVs compared to regular cars. In the area of smart home gadgets [29] and social media [27], effort expectancy has a positive relationship with the perceived advantages from employing the innovation. This study proposed the likelihood of individuals selecting an innovation whose benefits make it easy to use. Accordingly, the following hypothesis was formulated:

Hypothesis (H1c). Perceived effort expectancy has a positive impact on the perceived advantages of adopting $A V s$.

\subsection{Perceived Drawbacks}

Based on the literature, the present study defined risk as encompassing every possible danger or flaw that is implicit in a service [26], which can include both financial and nonfinancial risks [28]. Financial cost comprises the true cost of the product, and non-financial costs mostly comprise time, effort, technicality (ease of use), system reliability (fault-free system, constantly accessible and protected), connectivity (considering how immediate and straightforward the connection is), and efficiency (the duration of the loading and reply time) [28]. Regarding smart home gadgets [29], social media [27], decision making [31], and fintech adoption (which stands for financial technology service) [28], researchers revealed that the perceived risk has a negative link to behavioral intention. Regarding AVs, this study examined the perceived drawbacks as people's conceptions in connection with the possible risks of employing AVs. Accordingly, the following hypothesis was formulated:

Hypothesis (H2). Perceived drawbacks of utilizing AVs have a negative impact on the intention to adopt.

\subsubsection{Security Risk}

According to previous studies, security risk examines the extent of the protection that is given by a setup $[29,31]$. In the context of this study, it refers to the extent to which driving AVs might be insecure. Pertaining to smart home gadgets [29], security risk has a positive link to the perceived risk. Further, regarding fintech acquisition [32], the security risk is the second key salient intention (following legal risk), with a positive link to the perceived drawbacks that are connected with utilizing innovations. This study proposed that people are less likely to select the innovations with a high level of insecurity, as they are deemed risky. Accordingly, the following hypothesis was formulated:

Hypothesis (H2a). Security risk has a positive impact on perceived drawbacks of AV adoption.

\subsubsection{Performance Risk}

Derived from the literature, performance risk is the low or non-existent likelihood of satisfying people's needs [32,33]. The present study defined performance risk as the risk that driving AVs might be less useful than expected. In the area of fintech acquisition [32], performance risk was the most important measure of perceived risk when using fingerprint ATMs by prospective adopters, whereas, for smart home gadgets [29], it had a positive link to the perceived drawbacks. This study proposed that individuals are less likely to select innovations that fail to meet their specifications [34]. Finally, according to [35], performance risk is among the risks of using AVs. Accordingly, the following hypothesis was formulated: 
Hypothesis (H2b). Performance risk has a positive impact on the perceived risk regarding the adoption of $A V s$.

\subsubsection{Time Risk}

According to the literature, time risk means that using some technology may waste time [30]. In the context of this study, time risk refers to the possibility that AVs might need more time for switching and operating than regular cars. Regarding smart home devices [29], time is the second key significant construct, after privacy risk, and positively associated with the perceived drawbacks of using the innovation. This study proposed that people are less likely to select an innovation with a tendency to waste time [34]. Accordingly, the following hypothesis was formulated:

Hypothesis (H2c). Time risk has a positive impact on the perceived drawbacks of AV adoption.

\subsubsection{Financial Risk}

According to the literature, financial risk concerns the possibility of the price of acquiring or supporting a particular system being very high [19]. The present study defined financial risk as the high cost of buying and operating AVs. In decision making [31] and fintech adoption [32], analysts identified a positive relationship between financial risk and perceived risk. A study [21] on tablet PC adoption found that the technology price was the key construct with a positive link to the perceived drawbacks and reducing the pace of acquisition of tablet PCs. Regarding AVs, this study defined the perceived financial risk as what people believe in relation to the possible cost of acquiring AVs; they are less likely to select expensive innovations. Accordingly, the following hypothesis was formulated:

Hypothesis (H2d). Financial risk has a positive influence on the perceived drawbacks of $A V$ adoption.

\subsubsection{Psychological Risk}

Based on the literature, psychological risk is the extent of panic that is linked to utilizing an innovation [15]. In the context of this study, it refers to the chance of negatively disturbing the client's comfort during driving [36]. In the area of establishing and disseminating health details through social media, [27] ascertained that the psychological risk of an innovation emerged as the key point with a strong link to the perceived risk. As pertains to this study, individuals have a lower likelihood of selecting innovations that worry them. Accordingly, the following hypothesis was formulated:

Hypothesis (H2e). Psychological risk has a positive influence on the perceived drawbacks of the adoption of $A V s$.

\subsection{Extending the NVM}

\subsubsection{Personal Innovativeness}

Based on previous studies, personal innovativeness concerns the client's willingness to consider current technologies [37]. The present study defined personal innovativeness as the desire to drive an AV. The outcome is an improvement in the individual's trust and satisfaction with using the innovation [31]. Thus, personal innovativeness has a positive influence on the intention to adopt [38], the perceived advantages, and the negatively perceived drawbacks of present clients and prospective adopters [36]. Prospective adopters are more likely to accept the risk, whereas non-adopters are less willing. Concentrating on prospective adopters, this research suggested that:

Hypothesis (H3). Personal innovativeness has a positive impact on the perceived advantages.

Hypothesis (H4). Personal innovativeness has a negative impact on the perceived drawbacks. 
Hypothesis (H5). Personal innovativeness has a positive impact on the intention to adopt.

\subsubsection{Social Influence}

Based on the literature, social influence is explained as another person's impact on one's own plans [39]. In the context of this study, social influence refers to the impact of others on the intention to adopt AVs. Grounded in the UTAUT, social influence has a positive influence on the intention to adopt [24]. According to [40], it has a positive influence on behavioral intent and a negative impact on perceived drawbacks, implying that persons who want to meet others' expectations have minimal concerns regarding the perceived drawbacks [19]. Accordingly, the following hypothesis was formulated:

Hypothesis (H6). Social influence has a negative impact on the perceived drawbacks.

Hypothesis (H7). Social influence has a positive impact on the intent to adopt.

\subsubsection{Alternatives}

According to the previous literature, alternatives consist of different solutions to selecting the ideal innovation [20]. The present study defined alternatives as competing solutions to driving, for instance, employing a personal driver or taking a taxi. Alternatives have a significant effect on the client's resolutions [41]. Without a doubt, every client is willing to evaluate the expected product's advantages and drawbacks against those of competitors, finally selecting the preferred product with greater benefits and lower costs. Regarding [20], in the area of tablet PC acquisition, the alternatives had a negative impact on acquisition. This study proposed that people are less likely to select an innovation if preferable choices exist (for instance, hiring a driver or taking a taxi). Accordingly, the following hypothesis was formulated:

Hypothesis (H8). Alternatives have a negative impact on the intention to adopt.

To conclude, key relative constructs (17 hypotheses) that are associated with the perceived advantages and perceived drawbacks were selected from various fields, including smart home gadgets and social media. This expanded the existing NVM model through the addition of three constructs, namely, personal innovativeness, social influence, and alternatives' attractiveness, as significant independent variables that might affect the intention to adopt. Figure 2 shows the proposed extended NVM model.

The suggested model contains 14 constructs and 17 hypotheses. Three constructs with a link to the actual NVM, perceived advantages, perceived drawbacks, and adoption intention were regarded as dependent variables. Each contained a subgroup of independent variables. The key dependent variable that signified the purpose of this research was adoption intention, which was strongly influenced by perceived advantages, perceived drawbacks, alternatives, personal innovativeness, and social influence.

\section{Methodology}

\subsection{Sample and Data Collection Procedure}

The target population for the research was Saudi women, who represented a real sample of novice drivers, as they had previously been prohibited from driving for much more than 50 years [7]. Gathering data was undertaken via a study questionnaire. This study used purposive or judgmental sampling, which is based on the assumption that nominated sample constructs are representatives of the population of interest and are likely to assist the research's objective [42]. The reason this sampling technique was chosen is that AVs are not yet available to Saudi individuals; there is only a single place offering AVs in Saudi Arabia, namely, the Saudi Telecommunication Company (STC). In order to select appropriate respondents, this study developed a set of criteria. The first criterion was related to the individual's characteristics. The second criterion was related to the level 
of automation. While there are five different levels of AVs, ranging from level zero, which is totally controlled by humans, to level 5, which is completely controlled by machines [13], the second criterion concerned choosing a level $4 \mathrm{AV}$ for this study, i.e., the type that can drive itself but with human interference in case of emergency. The details regarding the requirements for individuals and the $\mathrm{AVs}$ that were selected for this study were as follows: (1) participants must be female novice drivers who had a year or less of driving experience and they must have experienced AVs prior to this study being conducted; (2) the AV level required for this paper was level 4 , which is able to move between two different points without human interference.

As it is difficult to calculate the actual number of Saudi female novice drivers, the $G^{*}$ power tool was used to do different analysis tests and to graphically display the results [43]. It was used to calculate the appropriateness of the sample size based on the number of predictors (independent variables) in the proposed model [43]. The result was a $90 \%$ chance that the R-squared (coefficient of determinates) value differed significantly from zero with 217 participants. A seven-month data collection period from early January 2020 to early July 2020; such a long period was used because of the COVID quarantine since collecting data during the quarantine was not easy due to health measures that prevented crowding and direct contact. A total of 1600 questionnaires were returned; 200 responses from those who had not yet experienced AVs were deleted and, thus, a total of 1400 responses was obtained. Potential participants were contacted face to face at the largest driving school for women in Riyadh to complete a fuller questionnaire and gain more accurate results than from the electronic ones. Regarding avoiding a sampling bias, see Section 5.1. Table 2 provides the background information about the participants.

Table 2. Background details about the participants $(\mathrm{N}=1400)$.

\begin{tabular}{cc}
\hline Category & Percentage \\
\hline Age (years) & $20 \%$ \\
$<30$ & $76 \%$ \\
$30-45$ & $3 \%$ \\
$46-50$ & $1 \%$ \\
$>50$ & \\
Profession & $10 \%$ \\
Student & $83 \%$ \\
Employed & $1 \%$ \\
Retired & $6 \%$ \\
Housewife & \\
Education Level & $1 \%$ \\
$<$ High school & $10 \%$ \\
$>$ High school & $50 \%$ \\
Bachelor & $39 \%$ \\
Postgraduate & \\
Marriage Status & $20 \%$ \\
Single & $80 \%$ \\
Married & \\
\hline Experience in driving a car & $20 \%$ \\
Yes & $80 \%$ \\
\hline No & $100 \%$ \\
\hline Experiencing AV prior to this survey (real observation) & $0 \%$ \\
Yes & \\
No & \\
\hline
\end{tabular}




\subsection{Measures}

The constructs were adapted from past research where feasible. According to [44], measuring responses on a five-point Likert-type was most efficient [44], in this case from strongly disagree to strongly agree. The indicators that were used to estimate the intention to adopt AVs were established based on the original NVM [18], although those relating to the perceived advantages and perceived drawbacks were modified from $[15,29]$, and those for performance expectancy were modified from [3]. Three of the indicators that were employed in measuring effort expectancy, security risk, time risk, and financial risk were modified from [15]. The indicators for estimating enjoyment were obtained from [18] and those for measuring performance risk were obtained from $[15,23]$. The indicators pertaining to social influence were from [38], and those for personal innovativeness were from $[29,45]$. The indicators for estimating the alternatives were modified for the AV context based on those employed in [21], and the ones to estimate psychological risk were modified from [22]. See Table 3 for a summary of the indicator sources. The initial indicators underwent preliminary testing with 60 participants of the target population and slight adjustments were made to the phrasing of many constructs to enhance the understanding. All indicators were validated by two experts in order to ensure the rephrasing of some items within the constructs.

Table 3. Sources of the indicators.

\begin{tabular}{cc}
\hline Constructs & Sources \\
\hline Perceived advantages & {$[15,24]$} \\
Performance expectancy & {$[3,15]$} \\
Enjoyment & {$[23]$} \\
Effort expectancy & {$[3,15]$} \\
Perceived drawbacks & {$[15,24]$} \\
Security risk & {$[15]$} \\
Performance risks & {$[15,23]$} \\
Time risks & {$[15]$} \\
Financial risk & {$[15]$} \\
Psychological risk & {$[18]$} \\
Alternatives & {$[31]$} \\
Social influence & {$[38]$} \\
Personal innovativeness & {$[24,41]$} \\
Adoption intention & {$[15,16]$} \\
\hline
\end{tabular}

\section{Data Analysis and Result}

\subsection{Common Method Bias Results}

Common method bias (CMB) occurs when the relationships between two or more constructs are measured with the same method [46], affecting the quality of the research findings [47]. In order to reduce $\mathrm{CMB}$ and to achieve stronger relationships between constructs, a set of strategies was used in this study. First, the questions were randomly ordered and the dependent and independent variables in the survey were clearly separated [47]. Moreover, a good coversheet and set of instructions were presented at the beginning of the questionnaire to avoid any misconceptions [46]. The survey was short and avoided any redundant measures or overlaps with the total of 38 questions [47]. Finally, CMB was tested in SmartPLS to ensure that all VIFs (factor levels) were the same as or less than 3.3 [48]. The results were all found to be lower than 3.3; therefore, the model can be considered free of common method bias [48].

Harman's single factor test was also applied to test for CMB [49] to ensure that the total variance of a single factor was less than $50 \%$ of the total variance [42]. This was done in SPSS by analyzing the dimension reduction, selecting all variables, and ensuring that the rotation method was none and the number of factors was one without rotation [42,49]. The results of Harman's test showed that a single factor accounted for $31.856 \%$ of the total 
variance, which is far less than $50 \%$ of the total variance, as shown in Table 4 . That is, there was no threat of CMB.

Table 4. Harman's single factor test result.

\begin{tabular}{ccccccc}
\hline & \multicolumn{3}{c}{ Initial Eigenvalues } & \multicolumn{2}{c}{ Extraction Sums of Squared Loadings } \\
\hline Component & Total & Variance \% & Cumulative \% & Total & Variance \% & Cumulative \% \\
\hline 1 & 18,476 & 31.856 & 31.856 & 18,476 & 31.856 & 31.856 \\
2 & 8219 & 14.170 & 46.026 & & & \\
3 & 6.618 & 11.410 & 57.457 & & \\
4 & 3.399 & 5.861 & 63.926 & & \\
5 & 2.529 & 4.417 & 67.767 & & \\
6 & 2.219 & 3.826 & 71.393 & & \\
\hline
\end{tabular}

\subsection{Measurement Model Assessment}

This assessment checks that the model is reliable and valid before further data analysis can be undertaken [50]. First, convergent validity can be estimated using the average variance extracted (AVE) criteria, factor loading, and composite reliability (CR) [50]. From Table 5, every construct loaded significantly on its corresponding construct, with no loading falling below 0.50 [51].

Table 5. Descriptive statistics of the items.

\begin{tabular}{|c|c|c|c|c|c|}
\hline Construct & Indicator/Q & Loading & Cronbach's Alpha & $\mathrm{CR}$ & AVE \\
\hline \multirow{4}{*}{ Intention to adopt $\mathrm{AVs}$} & AI1 & 0.90 & 0.95 & 0.96 & 0.87 \\
\hline & AI2 & 0.94 & & & \\
\hline & $\mathrm{AI} 3$ & 0.94 & & & \\
\hline & AI4 & 0.94 & & & \\
\hline \multirow[t]{3}{*}{ Perceived advantages } & PB1 & 0.92 & 0.93 & 0.95 & 0.83 \\
\hline & PB2 & 0.91 & & & \\
\hline & PB4 & 0.92 & & & \\
\hline \multirow[t]{3}{*}{ Performance expectancy } & PE2 & 0.90 & 0.87 & 0.91 & 0.72 \\
\hline & PE3 & 0.89 & & & \\
\hline & PE4 & 0.83 & & & \\
\hline \multirow[t]{2}{*}{ Effort expectancy } & EE1 & 0.92 & 0.90 & 0.93 & 0.78 \\
\hline & EE2 & 0.93 & & & \\
\hline \multirow{2}{*}{ Enjoyment } & ENJ1 & 0.95 & 0.93 & 0.95 & 0.90 \\
\hline & ENJ2 & 0.95 & & & \\
\hline \multirow{3}{*}{ Perceived drawbacks } & PRS1 & 0.99 & 0.99 & 0.99 & 0.99 \\
\hline & PRS2 & 0.99 & & & \\
\hline & PRS3 & 0.99 & & & \\
\hline \multirow[t]{2}{*}{ Security risk } & SR1 & 0.97 & 0.97 & 0.98 & 0.95 \\
\hline & SR4 & 0.97 & & & \\
\hline \multirow[t]{3}{*}{ Performance risk } & PR1 & 0.83 & 0.89 & 0.92 & 0.80 \\
\hline & PR3 & 0.87 & & & \\
\hline & PR4 & 0.96 & & & \\
\hline \multirow[t]{3}{*}{ Time risk } & TR2 & 0.91 & 0.86 & 0.91 & 0.79 \\
\hline & TR3 & 0.83 & & & \\
\hline & TR4 & 0.90 & & & \\
\hline
\end{tabular}


Table 5. Cont.

\begin{tabular}{|c|c|c|c|c|c|}
\hline Construct & Indicator/Q & Loading & Cronbach's Alpha & CR & AVE \\
\hline \multirow[t]{2}{*}{ Financial risk } & FR1 & 0.99 & 0.90 & 0.93 & 0.87 \\
\hline & FR3 & 0.99 & & & \\
\hline \multirow[t]{2}{*}{ Psychological risk } & PSR1 & 0.89 & 0.86 & 0.92 & 0.85 \\
\hline & PSR2 & 0.95 & & & \\
\hline \multirow[t]{3}{*}{ Personal innovativeness } & PI2 & 0.86 & 0.86 & 0.91 & 0.78 \\
\hline & PI3 & 0.86 & & & \\
\hline & PI4 & 0.92 & & & \\
\hline \multirow[t]{3}{*}{ Alternatives } & $\mathrm{A} 2$ & 0.96 & 0.92 & 0.95 & 0.87 \\
\hline & A3 & 0.87 & & & \\
\hline & A4 & 0.96 & & & \\
\hline \multirow[t]{4}{*}{ Social influence } & SI1 & 0.90 & 0.90 & 0.93 & 0.78 \\
\hline & SI2 & 0.84 & & & \\
\hline & SI3 & 0.92 & & & \\
\hline & SI4 & 0.87 & & & \\
\hline
\end{tabular}

The Cronbach's alphas and composite reliabilities (CRs) found that every construct was over 0.70 , and the average variance extracted (AVE) was greater than 0.50 , verifying the convergent validity. In order to assess the discriminant validity, this study used the heterotrait-monotrait ratio (HTMT) to measure the correlation between two constructs [52]. An HTMT close to 1 indicates the absence of discriminant validity [53]. Some writers recommend a threshold of 0.85 [52]. If the HTMT value is below 0.90 , discriminant validity is established between two reflective constructs [50]. In this study, all the HTMTs for all constructs were less than 0.90, as shown in Table 6, confirming the discriminant validity. Furthermore, the discriminant validity was tested for every construct such that the square root of its AVE was more than every correlation linking that construct and every other construct.

Table 6. Heterotrait-monotrait ratios (HTMTs) of the correlations.

\begin{tabular}{|c|c|c|c|c|c|c|c|c|c|c|c|c|c|c|}
\hline & 1 & 2 & 3 & 4 & 5 & 6 & 7 & 8 & 9 & 10 & 11 & 12 & 13 & 14 \\
\hline 1. Alternatives & & & & & & & & & & & & & & \\
\hline 2. Effort expectancy & 0.126 & & & & & & & & & & & & & \\
\hline 3. Enjoyment & 0.142 & 0.749 & & & & & & & & & & & & \\
\hline 4. Financial risk & 0.065 & 0.654 & 0.828 & & & & & & & & & & & \\
\hline 5. Intention to adopt AVs & 0.154 & 0.620 & 0.719 & 0.480 & & & & & & & & & & \\
\hline 6. Perceived advantages & 0.108 & 0.888 & 0.864 & 0.769 & 0.714 & & & & & & & & & \\
\hline 7. Perceived drawbacks & 0.377 & 0.082 & 0.125 & 0.099 & 0.059 & 0.101 & & & & & & & & \\
\hline 8. Performance expectancy & 0.103 & 0.737 & 0.769 & 0.669 & 0.601 & 0.820 & 0.096 & & & & & & & \\
\hline 9. Performance risk & 0.066 & 0.207 & 0.031 & 0.043 & 0.119 & 0.064 & 0.020 & 0.240 & & & & & & \\
\hline 10. Personal innovativeness & 0.082 & 0.677 & 0.636 & 0.504 & 0.676 & 0.721 & 0.047 & 0.530 & 0.187 & & & & & \\
\hline 11. Psychological risk & 0.009 & 0.085 & 0.070 & 0.051 & 0.060 & 0.116 & 0.018 & 0.158 & 0.561 & 0.074 & & & & \\
\hline 12. Security risk & 0.018 & 0.086 & 0.018 & 0.048 & 0.047 & 0.119 & 0.032 & 0.184 & 0.592 & 0.140 & 0.828 & & & \\
\hline 13. Time risk & 0.155 & 0.099 & 0.019 & 0.015 & 0.081 & 0.058 & 0.111 & 0.056 & 0.225 & 0.099 & 0.105 & 0.144 & & \\
\hline 14. Social influence & 0.072 & 0.532 & 0.464 & 0.334 & 0.691 & 0.639 & 0.038 & 0.495 & 0.166 & 0.743 & 0.082 & 0.089 & 0.155 & \\
\hline
\end{tabular}

The reliability of the study was measured through both the composite reliability and Cronbach's alpha [54], as shown in Table 5. Altogether, the constructs scored 0.70 or above; thus, they were reasonably reliable [54]. The measurement model assessment showed that all items were found to be acceptable. The initial model with 35 observed indicators was therefore verified. 


\subsection{Structural Model Assessment}

After the measurement model was successfully validated, the structural model was analyzed, representing the relationships between the constructs. The structural model assessment includes the calculation of $\mathrm{R}^{2}$ and the path coefficients [55].

\subsubsection{The Coefficient of Determination $\left(\mathrm{R}^{2}\right)$}

Path coefficients represent the strong association points between the dependent and independent variables. Assessment of the $\mathrm{R}^{2}$ values signifies the amount of variance in the dependent variable explained by the independent variables. The $\mathrm{R}^{2}$ value should be high enough for the model, with 0.670 considered to be significant, values around 0.333 to be average, and values of 0.190 and lower to be weak [55]. Table 7 presents the $\mathrm{R}^{2}$ for the structural model in this study. The $\mathrm{R}^{2}$ value for the intention to adopt was average at 0.58 , with 0.85 for the perceived advantages (significant), 0.615 for the perceived drawbacks, with a weak result for alternatives.

Table 7. $\mathrm{R}^{2}$ and $\mathrm{F}^{2}$ for the endogenous latent variable.

\begin{tabular}{cccc}
\hline Construct & $\mathbf{R}^{\mathbf{2}}$ & $\mathbf{F}^{\mathbf{2}}$ & Value \\
\hline Alternatives & 0.004 & 0.014 & Weak \\
Intention to Adopt AVs & 0.564 & - & Average \\
Perceived advantages & 0.859 & 0.175 & Significant \\
Perceived drawbacks & 0.025 & 0.002 & Weak \\
\hline
\end{tabular}

The size of the $\mathrm{F}^{2}$ effect is used to measure the impact of a specific predictor construct on a dependent construct [55]. Table 7 shows that perceived advantages had the largest effect in the model (specifically on the intention to adopt) compared with the perceived drawbacks, alternatives, and intention to adopt.

\subsubsection{Hypothesis Testing ( $p$-Value)}

The hypotheses were verified by evaluating the statistical importance of the path coefficients using t-statistics, which were computed by means of the bootstrap resampling method using 500 samples, as shown in Table 8.

Table 8. Hypothesis testing results.

\begin{tabular}{cccccc}
\hline$\#$ & Hypothesis & $\begin{array}{c}\text { Path } \\
\text { Coefficients }\end{array}$ & T-Value & $p$-Value & $\begin{array}{c}\text { Empirical } \\
\text { Evidence }\end{array}$ \\
\hline H1 & Perceived advantages $\rightarrow$ Intention to adopt AVs & 0.377 & 13.169 & 0.000 & Significant $\left(^{* * *} p\right)$ \\
H1a & Performance expectancy $\rightarrow$ Perceived advantages & 0.177 & 11.022 & 0.000 & Significant $\left(^{* * *} p\right)$ \\
H1b & Enjoyment $\rightarrow$ Perceived advantages & 0.375 & 16.159 & 0.000 & Significant $\left(^{* * *} p\right)$ \\
H1c & Effort expectancy $\rightarrow$ Perceived advantages & 0.370 & 18.587 & 0.000 & Significant $\left(^{* * *} p\right)$ \\
H2 & Perceived drawbacks $\rightarrow$ Intention to adopt AVs & -0.029 & 1.563 & 0.098 & Not significant \\
H2a & Security risk $\rightarrow$ Perceived drawbacks & 0.053 & 0.713 & 0.508 & Not significant \\
H2b & Performance risk $\rightarrow$ Perceived drawbacks & -0.010 & 0.293 & 0.793 & Not significant \\
H2c & Time risk $\rightarrow$ Perceived drawbacks & 0.105 & 3.976 & 0.000 & Significant $\left({ }^{* * *} p\right)$ \\
H2d & Financial risk $\rightarrow$ Perceived drawbacks & 0.139 & 3.768 & 0.000 & Significant $\left({ }^{* * *} p\right)$ \\
H2e & Psychological risk $\rightarrow$ Perceived drawbacks & -0.032 & 0.301 & 0.676 & Not significant \\
H3 & Personal innovativeness $\rightarrow$ Perceived advantages & 0.125 & 9.392 & 0.000 & Significant $\left({ }^{* * *} p\right)$ \\
H4 & Personal innovativeness $\rightarrow$ Perceived drawbacks & -0.031 & 0.882 & 0.390 & Not significant \\
H5 & Personal innovativeness $\rightarrow$ Intention to adopt AVs & 0.151 & 4.369 & 0.000 & Significant $\left({ }^{* * *} p\right)$ \\
H6 & Social influence $\rightarrow$ Perceived drawbacks & -0.021 & 0.846 & 0.536 & Not significant \\
H7 & Social influence $\rightarrow$ Intention to adopt AVs & 0.325 & 8.348 & 0.000 & Significant $\left(^{* * *} p\right)$ \\
H8 & Alternatives $\rightarrow$ Intention to adopt AVs & 0.084 & 4.512 & 0.000 & Significant $\left({ }^{* * *} p\right)$ \\
H9 & Social influence $\rightarrow$ Alternatives & 0.066 & 2.527 & 0.011 & Strong $\left({ }^{* *} p\right)$ \\
\hline
\end{tabular}


The $t$-value and the degrees of freedom (DF) were used to calculate the $p$-value for each of the 17 hypotheses [55], which are all shown in Table 8. All the hypotheses were supported, except for hypotheses H2, H2a, H2e, H2b, H6, and H4 (see Figure 3). From the hypotheses, perceived advantages exhibited a positive relationship with the intention to adopt AVs $(B=0.37, p<0.000)$; hence, $\mathrm{H} 1$ was supported. Of its components, performance expectancy $(B=0.20, p<0.000)$, enjoyment $(B=0.26, p<0.000)$, and effort expectancy $(B=0.44, p<0.000)$ exhibited positive relationships with perceived advantages, supporting $\mathrm{H} 1 \mathrm{a}, \mathrm{H} 1 \mathrm{~b}$, and $\mathrm{H} 1 \mathrm{c}$, respectively. Unexpectedly, the perceived risk had no significant link with the intention to adopt $\mathrm{AVs}(\Omega=-0.029, p>0.05)$; thus, $\mathrm{H} 2$ was not supported. Its components, security risk $(\beta=-0.040, p>0.05)$, performance risk $(\beta=-0.003, p>0.05)$, and psychological risk $(\beta=-0.025, p>0.05)$ were also found to be negatively related to perceived drawbacks, rejecting $\mathrm{H} 2 \mathrm{a}, \mathrm{H} 2 \mathrm{~b}$, and $\mathrm{H} 2 \mathrm{e}$, respectively. However, time risk $(B=0.105, p<0.000)$ and financial risk $(\beta=0.142, p<0.000)$ had positive links with perceived drawbacks, supporting $\mathrm{H} 2 \mathrm{c}$ and $\mathrm{H} 2 \mathrm{~d}$, respectively. That is, not even security risk, performance risk, or psychological risk made a contribution to the perceived risk.

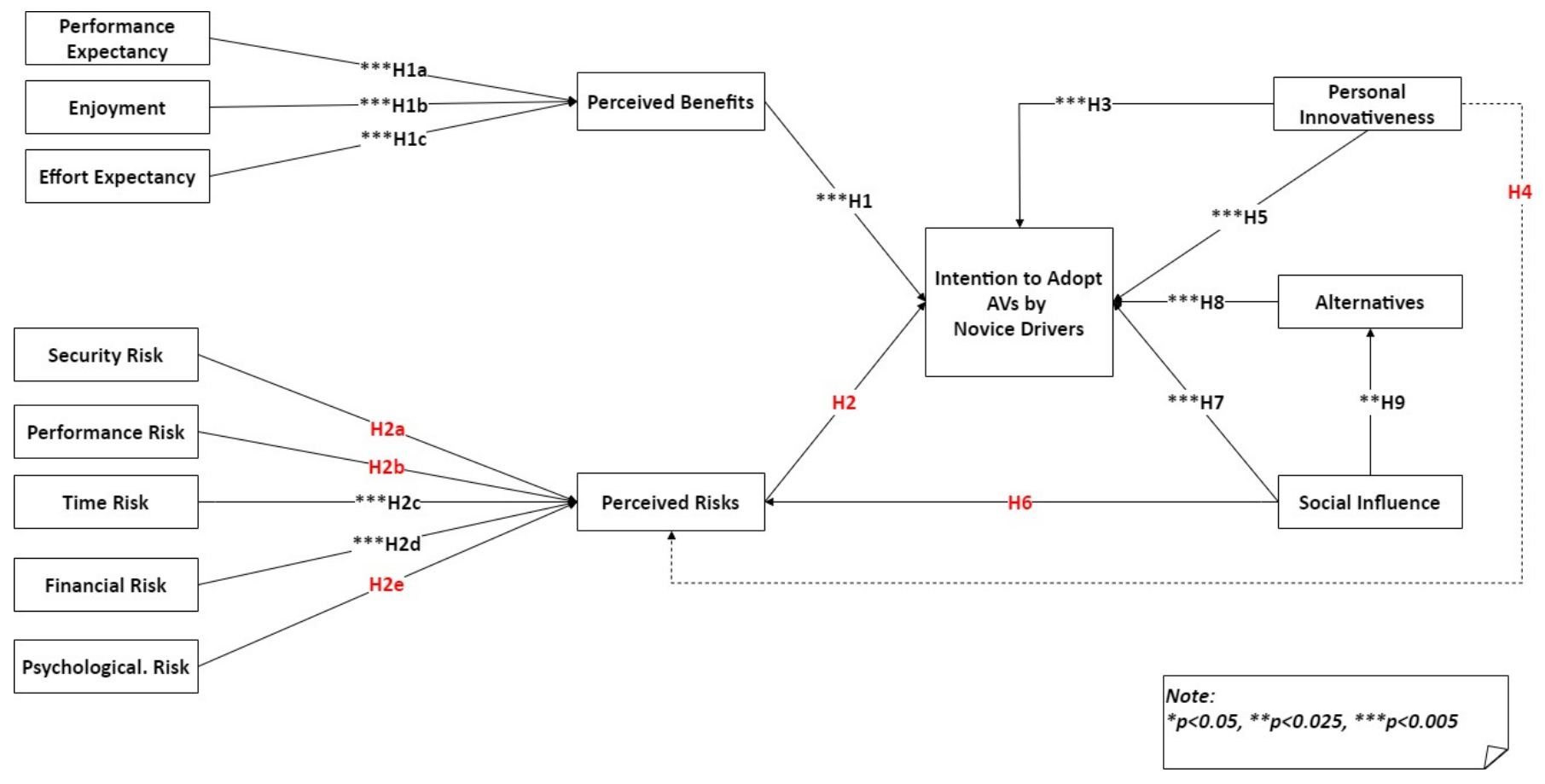

Figure 3. Proposed model with all hypotheses (red indicates unsupported hypothesis).

For the extended version of the NVM, as hypothesized, personal innovativeness was positively related to the intention to adopt $\mathrm{AVs}(\Omega=0.151, p<0.000)$, as were alternatives $(B=0.084, p<0.000)$ and social influence $(B=0.325, p<0.000)$, supporting H5, H8, and H7, respectively.

In addition, personal innovativeness was positively related to perceived advantages $(ß=0.134, p<0.000)$, and social influence was positively related to alternatives $(\beta=0.066$, $p<0.000)$; thus, H3 and H9 were supported, respectively. However, personal innovativeness was negatively related to perceived drawbacks $(B=-0.041, p>0.05)$, and social influence was negatively related to perceived drawbacks $(B=-0.008, p>0.05)$; thus, neither H4 nor H6 was supported, respectively. The model could thus explain $69 \%$ of the variance in perceived advantages, $24 \%$ of the variance in perceived risk, and $48 \%$ of the variance in the intention to adopt AVs. The structural paths were tested in the final model (Figure 4). 


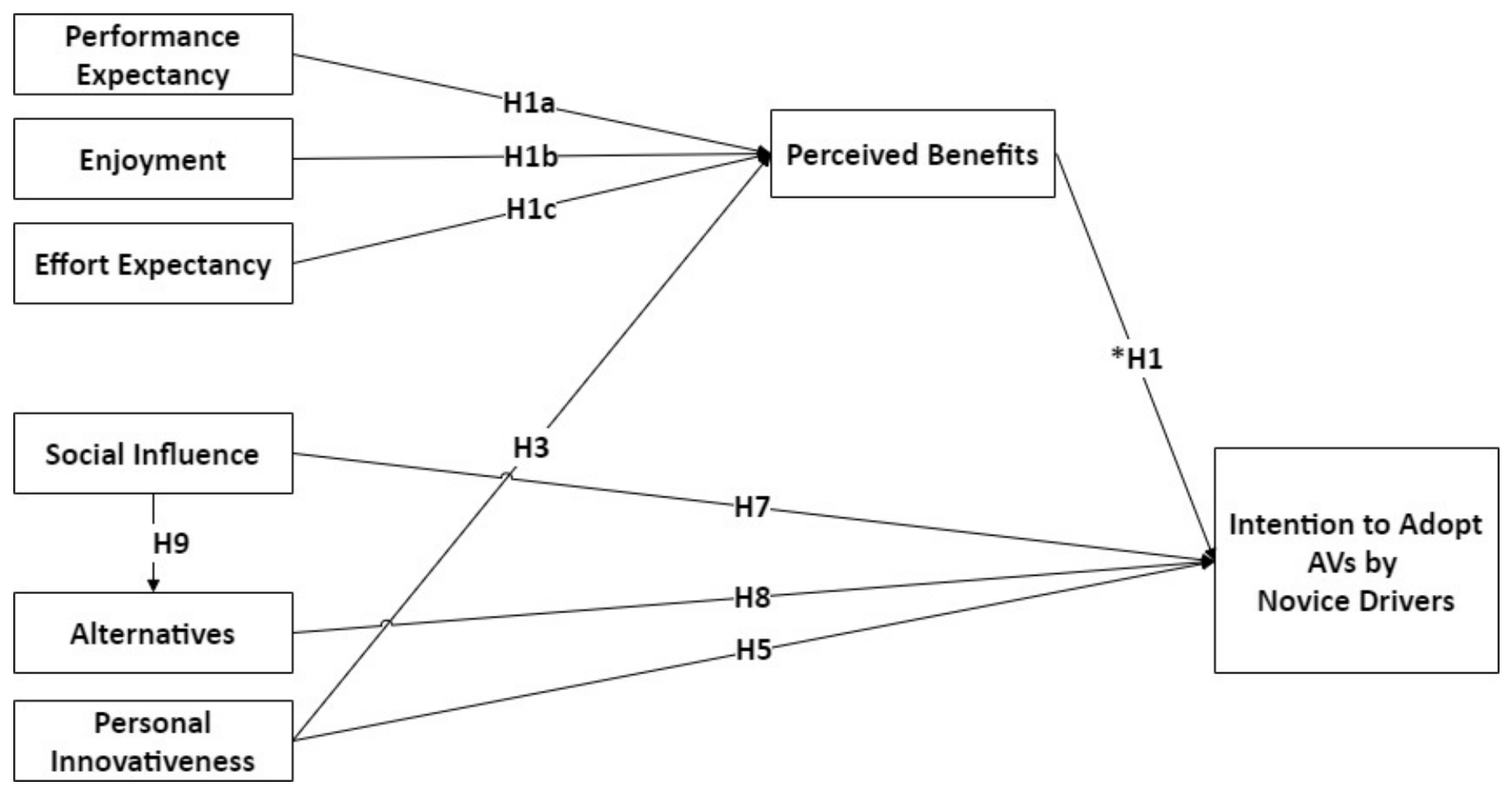

Figure 4. Final model.

\section{Discussion}

This research evaluated the influence of different constructs on individuals' intent to adopt AVs. This research applied a net valence model to identify the significant positive and negative constructs, also enhancing it with new extra constructs: alternatives, personal innovativeness, and social influence.

The main goal of the study was to produce a model to explain the factors that influenced the intention of Saudi female novice drivers to adopt AVs. After conducting the assessment of the measurement and structural models, the adoption model was established, as shown in Figure 2. The model included three dependent constructs-perceived advantages, alternatives, and intention to adopt-and five independent constructs-performance expectancy, enjoyment, effort expectancy, personal innovativeness, and social influence. Nine relationships were proposed to explain the model. After the data analysis process, eight insignificant relationships were eliminated from the adoption model. The nine remaining significant relationships were found to be appropriate for explaining the adoption model for AVs, as shown in Figure 4.

Second, this research established positive and negative constructs that were based on previous studies from various disciplines and clarified the influence of these constructs on individuals' risk and benefit perceptions of AV adoption. To the best of the authors' knowledge, past studies failed to examine the entire range of possible perceived benefit and risk constructs of using AVs. The outcomes revealed that during the consideration of the possible benefits that are linked to AVs, individuals concentrated on the degree to which they enhanced achievement, reduced effort, and minimized people's worries during driving.

In the field of smart homes, the design and mobility of a briefcase house as an IoT space allowed it to interact with the user and the surrounding space [15]. AVs use basic technologies similar to smart homes, such as an Internet connection, user interfaces, and wireless networks [28]. Therefore, most of the benefits and risks that were measured in this study were basically guided by the field of smart homes as evidence that both fields are emerging technologies and face similar benefits/risks [33]. Like smart homes, this study's results indicated the significant association of perceived advantages $(\mathrm{H} 1)$ with AVs 
adoption; however, it is very important to be aware of the different kinds of risk. Moreover, like [15], this study revealed the significant association of performance expectancy (H1a) and effort expectancy (H1c) regarding AV adoption. In conclusion, the field of smart homes can support the field of AVs with a variety of factors in future studies.

Although the outcomes revealed an insignificant association between perceived risk (H2) and AV adoption, consumers should be vigilant when deciding to adopt AVs. Hence, AV providers need to minimize the risks that are linked to using their vehicles. The outcomes can be beneficial to providers in making decisions about which kinds of risk to concentrate on. For instance, because time $(\mathrm{H} 2 \mathrm{c})$ and financial risks $(\mathrm{H} 2 \mathrm{~d})$ were the only risks that had a significant impact on perceived risk, marketers need to concentrate on the price of AVs and the length of time required to successfully establish and operate the vehicles.

Among the five suggested measurements of risk, finance $(\mathrm{H} 2 \mathrm{~d})$ and time $(\mathrm{H} 2 \mathrm{c})$ were the only two that had a significant impact on the perceived risks that prospective users faced regarding successfully buying and operating AVs. Unlike [15], who found a negative association between financial and time risks and the intention to adopt new technologies, this research confirmed that there was a strong association, with perceived cost being a constituent of the overall perceived risk. The impact of time risk shows consistency in practice, as individuals worry about potential time loss, such as disruption to daily activities, and expect products to have time warranties. Providers also need to concentrate on designing their products to be time-saving $(\mathrm{H} 2 \mathrm{c})$ and needing less time to become familiar, further lowering the perception of time risk. Individuals were also concerned about money (H2d).

Security risk $(\mathrm{H} 2 \mathrm{a})$, performance risk $(\mathrm{H} 2 \mathrm{~b})$, and psychological risk (H2e) were found to be insignificant. It may be the case that, with the maturity of the AV technology, individuals consider it to be less vulnerable to be hacked such that security $(\mathrm{H} 2 \mathrm{a})$ is not significant in their risk perceptions, despite [29] discovering that security is the most commonly perceived risk of smart technologies. Alternatively, clients may be insufficiently aware of potential security risks and their consequences. Future researchers could examine the awareness and knowledge of particular forms of security. AVs also appear to be less affected by total risk perceptions than in many studies. Finally, unlike [11], the outcomes of this research implied that psychological risk (H2e) had a negative impact on perceived drawbacks. Similarly, although [15] found a positive influence of performance risk (H2b) and security risk ( $\mathrm{H} 2 \mathrm{a})$ on perceived drawbacks in the field of smart homes, this study revealed a negative association toward the perceived drawbacks of AVs.

The outcomes of this research also revealed a direct link between the intent to adopt AVs and three new constructs: alternatives (H8), social influence (H7), and personal innovativeness $(\mathrm{H} 3, \mathrm{H} 5)$. The impact of these constructs on individuals' intention to adopt AVs has largely been ignored $[1,3,10]$.

Unlike [21], who found a negative influence of alternatives (H8) on the adoption intention of innovation, this study revealed a positive association of alternatives with AV adoption. Many customers may compare the benefits and sacrifices of a new technology with those of alternatives [31]. Hence, competitive alternatives to AVs, such as hiring personal drivers or taking taxis, can affect adoption by individuals. Although the outcomes revealed a positive association of alternatives with AV adoption, marketers need to be aware that the existence of different driving alternatives is a major challenge. From research on tablet PCs [21], alternatives were indicated as the initial and key construct that negatively impacted their adoption. However, the outcomes of this research implied that the alternatives had a positive impact on AV adoption. The absence of a link could be because the increase in the use of smartphones and other innovations strengthened an assumption that driving AVs is straightforward and, therefore, the personal energy required appeared to be of little impact.

This study revealed a significant association of social influence (H7) with AV adoption. According to [19], social influence can change people's opinions on the usefulness of new 
technology. Hence, marketers need to concentrate on the overall social perception of AVs. Social advertising and promotion can explain how AVs connect and protect families and friends. According to [40], "consumers are going to influence other consumers by writing reviews and giving suggestions by using face-face and social media tools"; hence, social influence plays a critical role regarding adopting AVs.

Finally, this study revealed the significant association between personal innovativeness (H5) and AV adoption. Like [29] with ATM fingerprinting, personal innovation was found to have a favorable impact on both present and prospective adopters' adoption intentions. Hence, marketers may facilitate the adoption of AVs throughout the early phases of the technology's marketing by targeting customers with high levels of personal innovativeness. These consumers have a more positive attitude toward the adoption of AVs than other customers.

This work has contributed to research by using the NVM in this context for the first time. Enjoyment, effort expectancy, performance expectancy, time risk, privacy risk, social influence, personal innovativeness, and alternatives seem to possess harmonious effects across various technology environments $[15,21,29,40]$, whereas the effects of security risk, performance risk, and psychological risk appear to be more background-specific.

Generally, the contributions of this research to the literature are the clarification of the impact of positive and negative constructs on the adoption of AVs, and expanding the NVM with the three extra constructs: alternatives, social influence, and personal innovativeness. Although not every hypothesis was supported, the NVM indicated that some variance in every dependent variable was explained by the model ( $69 \%$ of perceived advantages, $24 \%$ of perceived risk, and $48 \%$ of intention to adopt AVs), giving powerful approval for the model.

In addition, the results gave significant insight into the impact of alternatives, personal innovativeness, and social influence on the adoption of AVs. Nevertheless, using the NVM meant that some benefit/risk constructs may not be significant. For instance, as psychological risk appeared not to be a problem during the adoption of AVs, its insignificant impact showed consistency with the perception of clients. However, previous studies that used the NVM revealed the opposite; for instance, [22] discovered that only psychological risk had a significant impact on Italians' health information seeking.

Finally, unlike previous studies on AVs, which found trust (as a single construct) to be the most significant factor that influenced the adoption negatively $[1,3,10]$, this study measured five different kinds of risk (five different constructs) to calculate exactly which risk was the real reason that prevented consumers' trust. As clarified throughout this discussion, of the five suggested measurements of risk, only financial (H2d) and time risks (H2c) had a significant impact on the perceived drawbacks.

\section{Conclusions}

The main contribution of the study was the development of the proposed model, which represented female novice drivers from the biggest driving school in Riyadh, Saudi Arabia. Furthermore, the adoption of AVs by novice drivers could provide ways in which to drive safely, avoid accidents, and feel more confident. Meanwhile, the recommendations to developers and manufacturers of AVs could result in them attracting more novice drivers to their market, increasing sales, improving the services provided, creating a competitive atmosphere with companies, and identifying the benefits and risks that are evaluated by individuals regarding $\mathrm{AV}$ adoption. The findings confirmed the value of extending NVM to determine novice drivers' intentions to adopt AVs. This study made significant theoretical and practical contributions.

\subsection{Implications for Theory}

The major theoretical contribution of this study was the formation of a new NVM model by extending the original NVM with three more constructs (social influence, personal 
innovativeness, and alternatives attractiveness). According to a recent comprehensive review, the NVM model has not been applied in the field of AVs.

The current research has many significant theoretical implications, the first of which is its use of the NVM to evaluate individuals' intention to adopt AVs for the first time. The outcomes revealed that perceived advantages were strongly linked to this intention, while perceived risk failed to have a significant impact. Individuals had a tendency to accept the possible risks and concentrate instead on the possible benefits resulting from AVs. Hence, this theoretical model helped to explain the likelihood of individuals adopting AVs.

\subsection{Implications for Practice}

First, this study has practical implications for novice drivers to drive safely using AVs, avoid accidents, and feel safer and more confident. Second, it provides recommendations for car manufacturers and $\mathrm{AV}$ developers regarding how to attract novice drivers to their market, with the advantages delineated in the previous section.

This research also has key practical implications: first, some perceived advantages were significant in the adoption of AVs and others are not. Hence, during campaigns to encourage the use of AVs, marketers should concentrate on the benefits outlined above. Specifically, performance expectancy had a strong effect on perceived benefit; hence, marketers should emphasize how AVs can help to bring convenience to individuals' driving. Enjoyment and effort expectancy also had a significant impact; therefore, marketers should emphasize that their AVs will reduce stress and bring more fun into people's lives.

\subsection{Limitations and Future Work}

Gathering data from the whole population of Saudi female novice drivers was not possible, and the data from only 1400 respondents were examined. By the beginning of 2019, AVs were available in Saudi Arabia from only a single source, namely, the STC (Saudi Telecommunication Company); therefore, most of the targeted population had not yet experienced AVs. Even with the inclusion of participants from different backgrounds, this sample could show some bias, as it included women from only one area of Saudi Arabia, meaning that the outcomes may fail to satisfy individuals from other cultural backgrounds. Future research should consider variations in cultural background.

Nonetheless, the limitations open avenues for several intriguing possibilities for future research. For instance, researchers might evaluate the significance of other risk constructs in individuals' overall perceived risk, as the dimensions that were evaluated in this research explained less than half of the variance. Further exploration might include the influence of other constructs in moderating the link between the perceived benefit/risk and adoption intention. According to [15], subdivided participants into various groupings grounded on culture and established the difference arising from the impact of perceived enefits/risk on BYOD adoption intention were distinct across subgroups. As such, there is a possibility that individuals from different cultural backgrounds have distinct perceptions of benefits and risk, which, in turn, may impact their intention to adopt AVs. Research can also be undertaken to evaluate individuals' post-adoption satisfaction

Author Contributions: Writing-original draft preparation, A.A.A.; writing-review and editing, N.A.I. and M.A.A.-S. All authors have read and agreed to the published version of the manuscript.

Funding: This research received no external funding.

Institutional Review Board Statement: Not applicable.

Informed Consent Statement: Not applicable.

Data Availability Statement: Not applicable.

Conflicts of Interest: The authors declare no conflict of interest. 


\section{References}

1. Zoellick, J.C.; Kuhlmey, A.; Schenk, L.; Schindel, D.; Blüher, S. Assessing acceptance of electric automated vehicles after exposure in a realistic traffic environment. PLoS ONE 2019, 14, e0215969. [CrossRef]

2. Eisenberg, A. 5 Ways Artificial Intelligence is Impacting the Automotive Industry. Ignite. 2018. Available online: https: / /igniteoutsourcing.com/automotive/artificial-intelligence-in-automotive-industry/ (accessed on 22 September 2021).

3. Xu, Z.; Zhang, K.; Min, H.; Wang, Z.; Zhao, X.; Liu, P. What drives people to accept automated vehicles? Findings from a field experiment. Transp. Res. Part C Emerg. Technol. 2018, 95, 320-334. [CrossRef]

4. Saudi Gazette News. Business in Saudi Arabia Strikingly More Optimistic Now. Available online: https://www.eyeofriyadh. $\mathrm{com} /$ news / details/business-in-saudi-arabia-strikingly-more-optimistic-now (accessed on 13 July 2019).

5. Dubai News. Tesla's Autopilot Features Are FINALLY Available in the UAE. Available online: https://lovindubai.com/dubai/ the-self-driving-autopilot-feature-1 (accessed on 9 June 2019).

6. Mideast Beast News. Google's 'Driverless Car' Launches in Saudi Arabia. 2016. Available online: https://www.themideastbeast. com/google-car-launches-in-saudi/ (accessed on 5 January 2019).

7. CNN NEWS. Landmark Day for Saudi Women as Kingdom's Controversial Driving Ban Ends. CNN. 2018. Available online: https: / / edition.cnn.com/2018/06/23/middleeast/saudi-women-driving-ban-lifts-intl/index.html (accessed on 25 February 2019).

8. Alotaibi, O.M. Potential Demand for Public Transport in Riyadh City, Saudi Arabia. Ph.D. Thesis, Cardiff University, Cardiff, Wales, 2017.

9. Harper, C.D.; Hendrickson, C.T.; Mangones, S.; Samaras, C. Estimating potential increases in travel with autonomous vehicles for the non-driving, elderly and people with travel-restrictive medical conditions. Transp. Res. Part C Emerg. Technol. 2016, 72, 1-9. [CrossRef]

10. Kyu, J.; Gu, Y. Investigating the Importance of Trust on Adopting an Autonomous Vehicle. Int. J. Hum. Comput. Interact. 2015, 31, 692-702.

11. Liu, P.; Guo, Q.; Ren, F.; Wang, L.; Xu, Z. Willingness to pay for self-driving vehicles: Influences of demographic and psychological factors. Transp. Res. Part C Emerg. Technol. 2019, 100, 306-317. [CrossRef]

12. Kaur, K.; Rampersad, G. Trust in driverless cars: Investigating key factors influencing the adoption of driverless cars. J. Eng. Technol. Manag.-JET-M 2018, 48, 87-96. [CrossRef]

13. Zhang, T.; Tao, D.; Qu, X.; Zhang, X.; Lin, R.; Zhang, W. The roles of initial trust and perceived risk in public's acceptance of automated vehicles. Transp. Res. Part C Emerg. Technol. 2019, 98, 207-220. [CrossRef]

14. Panagiotopoulos, I.; Dimitrakopoulos, G. An empirical investigation on consumers' intentions towards autonomous driving. Transp. Res. 2018, 95, 773-784. [CrossRef]

15. Wang, X.; McGill, T.J.; Klobas, J.E. I Want It Anyway: Consumer Perceptions of Smart Home Devices- Net Valance Model NVMgood for Hypothesis. J. Comput. Inf. Syst. 2018, 60, 437-447.

16. Lai, P.C. The Literature Review of Technology Adoption Models and Theories for the Novelty Technology. JISTEM-J. Inf. Syst. Technol. Manag. 2018, 14, 21-38. [CrossRef]

17. Kim, H.W.; Chan, H.C.; Gupta, S. Value-based Adoption of Mobile Internet: An empirical investigation. Decis. Support. Syst. 2017, 43, 111-126. [CrossRef]

18. Fishbein, M. Readings in Attitude Theory and Measurement; Wiley: New York, NY, USA, 1967.

19. Guzzo, T.; Ferri, F.; Grifoni, P. A model of e-commerce adoption (MOCA): Consumer's perceptions and behaviours, social influence. Behav. Inf. Technol. 2016, 35, 196-209. [CrossRef]

20. Martin, E.W.; Shaheen, S.A. Greenhouse gas emission impacts of carsharing in North America. IEEE Trans. Intell. Transp. Syst. 2011, 12, 1074-1086. [CrossRef]

21. Kim, M.K.; Joo, C.; Park, J.H. Investigating the determinants of low adoption of tablet PCs in Korean firms: Effects of value perception and alternative attractiveness. Telemat. Informatics 2017, 34, 1557-1571. [CrossRef]

22. Li, X.; Wang, X.; Lin, X.; Hajli, M. Seeking and sharing health information on social media: A net valence model and cross-cultural comparison. Technol. Forecast. Soc. Chang. 2018, 126, 28-40. [CrossRef]

23. Weeger, A.; Gewald, H. Factors Influencing Future Employees Decision-Making to Participate in a BYOD Program: Does Risk Matter? In Proceedings of the 22st European Conference on Information Systems, ECIS 2014, Tel Aviv, Israel, 9-11 June 2014; pp. $1-14$.

24. Ryu, H.S. Understanding Benefit and Risk Framework of Fintech Adoption: Comparison of Early Adopters and Late Adopters. In Proceedings of the 51st Hawaii International Conference on System Sciences, Hilton Waikoloa Village, HI, USA, 3-6 January 2018; pp. 3864-3873.

25. Leicht, T.; Chtourou, A.; Youssef, B. Consumer innovativeness and intentioned autonomous car adoption. J. High Technol. Manag. Res. 2018, 29, 1-11. [CrossRef]

26. Macedo, I.M. Predicting the acceptance and use of information and communication technology by older adults: An empirical examination of the revised UTAUT2. Comput. Hum. Behav. 2017, 75, 935-948. [CrossRef]

27. Lin, T.C.; Wu, S.; Hsu, J.S.; Chou, Y.S. The integration of value-based adoption and expectation-confirmation models: An example of IPTV continuance intention. Decis. Support. Syst. 2012, 54, 63-75. [CrossRef]

28. Kim, Y.; Park, Y.; Choi, J. A study on the adoption of IoT smart home service. Total Qual. Manag. Bus. Excell. 2017, 28, 1149-1165. [CrossRef] 
29. Byun, S.; Byun, S.E. Exploring perceptions toward biometric technology (ATM finger print) in service encounters: A comparison of current users and potential adopters. Behav. Inf. Technol. 2013, 32, 217-230. [CrossRef]

30. Rosli, K.; Yeow, P.; Siew, E. Factors Influencing Audit Technology Acceptance by Audit Firms: A New I-TOE Adoption Framework. J. Account. Audit. Res. Pract. 2018, 2012, 1-11. [CrossRef]

31. Pham, T.-T.T.; Ho, J. What are the Core Drivers in Consumer Adoption of NFC-Based Mobile Payments. A Proposed Research Framework. In Proceedings of the PICMET '14 Conference: Portland International Center for Management of Engineering and Technology; Infrastructure and Service Integration, Kanazawa, Japan, 27-31 July 2014; pp. 3041-3049.

32. Bucchi, A.; Sangiorgi, C.; Vignali, V. Traffic Psychology and Driver Behavior. Procedia-Soc. Behav. Sci. 2012, 53, 972-979. [CrossRef]

33. Aldossari, M.Q.; Sidorova, A. Consumer Acceptance of Internet of Things (IoT): Smart Home Context- UTAUT. J. Comput. Inf. Syst. 2018, 60, 507-517. [CrossRef]

34. Dixit, V.; Chand, S.; Nair, D.J. Autonomous Vehicles: Disengagements, Accidents and Reaction Times. PLoS ONE 2016, 11, e0168054. [CrossRef] [PubMed]

35. Favarò, F.; Nader, N.; Eurich, S.; Tripp, M.; Varadaraju, N. Examining accident reports involving autonomous vehicles in California. PLOS ONE 2017, 12, e0184952. [CrossRef]

36. Rantanen, T.; Lehto, P.; Vuorinen, P.; Coco, K. Attitudes towards care robots among Finnish home care personnel-A comparison of two approaches. Scand. J. Caring Sci. 2018, 32, 772-782. [CrossRef] [PubMed]

37. Shaw, N.; Sergueeva, K. The non-monetary benefits of mobile commerce: Extending UTAUT2 with perceived value. Int. J. Inf. Manag. 2018, 45, 44-55. [CrossRef]

38. Lin, J.; Lobo, A.; Leckie, C. The influence of green brand innovativeness and value perception on brand loyalty: The moderating role of green knowledge. J. Strateg. Mark. 2019, 27, 81-95. [CrossRef]

39. Hsu, C.L.; Lin, J.C. Effect of perceived value and social influences on mobile app stickiness and in-app purchase intention. Technol. Forecast. Soc. Chang. 2016, 108, 42-53. [CrossRef]

40. Pitchayadejanant, K. Intention to Use of Smart Phone in Bangkok Extended Utaut Model by Perceived Value. In Proceedings of the International Conference on Management (ICM 2011) Proceeding, Penang, Malaysia, 13-14 June 2011.

41. Pham, T.; Ho, J. The effects of product-related, personal-related factors and attractiveness of alternatives on consumer adoption of NFC-based mobile payments. Technol. Soc. 2015, 43, 159-172. [CrossRef]

42. Kamakura, W.A. Common Methods Bias; Wiley International Encyclopedia of Marketing: Chichester, UK, 2010. [CrossRef]

43. Dattalo, P. Determining Sample Size: Balancing Power, Precision, and Practicality; Oxford University Press: Oxford, UK, $2008 ;$ p. 75.

44. Why Do You Use 5 Point Likert Scale and Not 7 Point Likert Scale for Getting Responses? Available online: https://www. researchgate.net/post/Why_do_you_use_5_point_Likert_scale_and_not_7_point_Likert_scale_for_getting_responses (accessed on 18 August 2021).

45. Talebian, A.; Mishra, S. Predicting the adoption of connected autonomous vehicles: A new approach based on the theory of diffusion of innovations DOI. Transp. Res. Part C Emerg. Technol. 2018, 95, 363-380. [CrossRef]

46. Jordan, P.J.; Troth, A.C. Common method bias in applied settings: The dilemma of researching in organizations. Aust. J. Manag. 2020, 45, 3-14. [CrossRef]

47. Podsakoff, P.M.; MacKenzie, S.B.; Lee, J.Y.; Podsakoff, N.P. Common method biases in behavioral research: A critical review of the literature and recommended remedies. J. Appl. Psychol. 2003, 88, 879-903. [CrossRef] [PubMed]

48. Kock, N. Common method bias in PLS-SEM: A full collinearity assessment approach. Int. J. E-Collab. 2015, 11, 1-10. [CrossRef]

49. Jakobsen, M.; Jensen, R. Common method bias in public management studies. Int. Public Manag. J. 2014, 18, 3-30. [CrossRef]

50. Hair, J.F.; Hult, G.T.M.; Ringle, C.M.; Sarstedt, M. A Primer on Partial Least Squares Structural Equation Modeling (PLS-SEM); Sage: Thousand Oaks, CA, USA, 2013.

51. Leguina, A. A primer on partial least squares structural equation modeling (PLS-SEM). Int. J. Res. Method Educ. 2015, 38, $220-221$. [CrossRef]

52. Henseler, J.; Ringle, C.M.; Sarstedt, M. A New Criterion for Assessing Discriminant Validity in Variance-based Structural Equation Modeling. J. Acad. Mark. Sci. 2015, 43, 115-135. [CrossRef]

53. David, A.; José, A. Assessing Convergent and Discriminant Validity in the ADHD-R IV Rating Scale: User-Written Commands for Average Variance Extracted (AVE), Composite Reliability (CR), and Heterotrait-Monotrait Ratio of Correlations (HTMT). Universidad Pablo de Olavide: Seville, Spain, 2015. Available online: https://www.academia.edu/30352304/Convergent_ validity_with_average_variance_extracted?auto=download (accessed on 22 September 2021).

54. Babbie, E. The Practice of Social Research; Wadsworth: Belmont, CA, USA, 1989.

55. Chin, W. The partial least squares approach to structural equation modeling. Mod. Methods Bus. Res. 1998, 295, $295-336$. 